\title{
Barriers to Value Specification when Carrying out Digitalization Projects
} Sten Grahn, Anna Granlund, Erik Lindhult

\author{
" Tell me how you will measure me, and I will tell you how I will behave." \\ Eliyahu Goldratt \\ The Haystack Syndrome, North River Press, 1991 \\ Author, Management Guru
}

\begin{abstract}
If digitalization projects aim to effectively create value for a company, one precondition is having a shared view among company staff and project members of what the "desirable" value is. However, it has been shown that few companies fully understand the value that digitalization projects can create for them, while many companies still launch digitalization projects without this understanding. This contributes to the current "alarmingly" low success rate for digitalization projects. Development of effective methods to specify the desired values of digitalization projects is thus important. One step in developing improved specification methods is to ask what the possible barriers are to improving current value specification practices. The purpose of the current study is to address this. We analyzed several digitalization projects regarding how specifications of desired project value were carried out, finding that very limited resources are spent on specifying desired values in digitalization projects, and that this limits project success. Likewise, there are several barriers to increasing resources for specifying desired values. Our findings contribute to understanding the development of value specification methods that aim to overcome these barriers and thus could help improve the success rate of digitalization projects.
\end{abstract}

\section{Introduction}

The growth of competition, environmental challenges, and market changes make it ever more important for companies nowadays to ensure that they utilize resources as efficiently and effectively as possible. Rapid technological development also increases the technological opportunities to streamline businesses and take fuller advantage of existing opportunities to create more value, reduce resource consumption, and increase competitiveness. The World Economic Forum's "Digital Transformation Initiative" (WEF, 2021) states, for example, that: "Digitalization has immense potential: we estimate it could deliver around $\$ 100$ trillion in value to business and society over the next decade". Carrying out effective digitalization projects has thus become an ever more important industrial and economic objective.

It has been shown, however, that few companies understand the value that digitalization can create for them (Gottlieb \& Willmott, 2014), and that many companies still launch digitalization projects without this understanding (Gutschem, 2014). As organizations can gain more value from projects when the desired value is unambiguously specified in the early front-end planning stage (Terlizzi et al., 2017), likewise the absence of adequate value specification contributes to the current "alarmingly" low success rate for digitalization projects, according to Ismail (2018). One motivation for this study was to contribute to methods that can increase the success rate of digitalization projects. The overarching purpose was also to contribute to the "servitization" field by taking a value recipient perspective, given that servitization literature mainly takes a supplier perspective. The two servitization literature reviews (Carlborg et al., 2014; Raddats et al., 2019) for example, only briefly mention the recipient perspective.

Nevertheless, the ability to specify and communicate desired value as a means to generating desirable project outcomes depends on a company being able to identify 


\section{Barriers to Value Specification when Carrying out Digitalization Projects}

\section{Sten Grahn, Anna Granlund, Erik Lindhult}

values that are commonly desired and incentivizing for project actors (Dass, 2014). Rapid technological and market developments lead us to assume that the quest for finding a commonly shared view of what a desired long-term outcome is, as well as a commonly shared view of what is resource-efficient, will become an increasing challenge. These developments may make it possible, as well as necessary, to carry out digitalization projects that could render significant parts of the project's own members, along with other company staff, redundant (Rifkin, 1995, 2014; Brynjolfsson \& McAfee, 2014), or lead to organizational changes that require new and demanding skills for the staff.

It can hence be challenging to find and use methods that specify the values desired in a way that incentivize all project members within companies, that support coordination of project resources when automation and other digitalization projects are carried out. but important to develop, as suggested by a comprehensive review on project front-end literature (Williams et al., 2019). This can be particularly important for small and medium sized enterprises (SMEs) as they report that the potential benefits of digitalization mainly have been framed towards larger firms (Müller et al., 2018).

Earlier, we studied how current value specification practice currently copes with potential disagreements regarding what counts as "desirable" long-term value from digitalization projects (Grahn et al., 2020). We found that potential disagreements generally were avoided by not specifying desired value at all, or with such low precision that there was nothing to disagree about. In that study, we also briefly mentioned other identified barriers. The present study expands on that previous study, intending to answer the question of what barriers exist to improving current value specification practices. Having a clear picture of existing barriers can guide companies to overcome these barriers, and possibly be a tool to increase the current success rate of digitalization projects.

The article is organized as follows: The first section describes how literature findings were used to shape the research approach. After describing our interview and workshop method, our empirical findings are presented. Finally, the empirical findings are analyzed, the identified categories of barriers are laid out in a table, and possible managerial implications of our research are outlined.

\section{Using Insights from Literature to Shape the Research Objective}

Projects can be viewed as a means to create potential value (Morris, 2009). If this potential value or benefit from a project is clarified before the project starts, the fundamental motivation behind the project decision also is clear (Project Management Institute, 2016). This activity of defining potential benefits, however often is given inadequate attention, (Breese et al., 2015; Badewi, 2016) incurring additional time and cost, as well as performance issues at later phases (Edkins \& Smith, 2012).

Digitalization projects have the potential to generate several different benefits for a company, for example, by creating new or increasing the existing customers' values, customers may be willing to pay more, or companies may be able to reduce the need for the resources, and costs required for value creation. In this study "value" was, hence, viewed as a vector containing several value "terms" such as production capacity, product usefulness, lead-time, useful information, etc. Identified resource requirements which create this Value (V) (i.e. resources to install, operate and maintain digital installations) were also viewed as a vector of several Resource "terms" $(R)$ such as $R$ (hours, machinery, maintenance/upgrade resources, etc). This study, then, observes how companies have treated their desired $\mathrm{V}$ creation and desired $\mathrm{R}$ reduction, and how different terms were weighted depending on the company's project specifications,

Stahel (2010) introduces the time factor concept, stressing the importance of recognizing that "performance" should be specified over a chosen time frame, that is, how created $V$ and reduced $R$ consumption should develop over a relevant timeframe. It has also been said that "The ability to learn faster than your competitors may be the only sustainable competitive advantage" (de Gues, 1988). An important outcome for any digitalization measure, thus, should be the achieving of as large an increase as possible for the fraction: (Created Value) / (Resource consumption required for Value creation) (V/R) over time. This indicates that industrial projects should secure both optimizability of tools, machinery, and production systems, providing secure preconditions for optimization, as well as contribute to full utilization of this optimizability. It was, therefore, relevant to observe how desired $V$ and desired reduction of $R$ were specified, 


\section{Barriers to Value Specification when Carrying out Digitalization Projects}

\section{Sten Grahn, Anna Granlund, Erik Lindhult}

in particular useful measurements of actual $\mathrm{V}$ and $\mathrm{R}$, in order to be able to increase V/R over time. (From this point on, "value" means "V/R over time".)

In summary, it was assumed that the ability to generate successful long-term value from digitalization projects is dependent on three main preconditions which specify how:

- Different value and resource terms should be prioritized and weighted.

- Desired increase of value over time, is to be created.

- Created value from the projects should be measured.

As the process for specifying the desired value of industrial digitalization projects was studied, it was relevant to reflect on possible barriers within the three aforementioned areas during this procedure.

It was also important to consider the already identified barriers for companies attempting to "servitize" their offers and shift focus from delivering products to creating customer value. Servitization studies that have taken this provider perspective have identified several barriers to this shift, for example, many customers are unaccustomed to the notion of paying for performance or function rather than the familiar concept of paying for products (Rexfelt \& Ornäs, 2009), or, on placing a value on having a need met, as opposed to placing a value on owning products (Baines et al., 2007). Customers may also see strategic barriers and may not want to engage in deeper collaboration with the provider, due to fears of valuable company information being shared with entities outside the firm (Matthyssens \& Vandenbempt, 2010). Other authors studying such barriers from the provider perspective mention issues related to lack of competency and skill (Lerch \& Gotsch, 2015) or inadequate economic and management support (Ormazabal et al., 2016). When clustering the identified value specification barriers, it was assumed that the various provider barriers could be mirrored as recipient barriers. that is, as barriers for technology receivers wanting to "servitize" their digitalization project procurement process and shift focus from buying technology to creating value. This research, thus, categorized the thematic clusters as follows: Cultural barriers $(\mathrm{Cu})$, Organizational barriers (Or), Competence barriers (Co), Support barriers (Su), and Other barriers (Ot). The data in each cluster was further submerged into suggested categories of barriers for each thematic cluster.

It is within such a context that this research asked the question: What barriers should be considered in seeking to improve current value specification practices?

\section{Research Method}

In order to identify barriers to value specification, the researchers interviewed companies regarding current specification practices and also held in-depth workshops with an international process industry company regarding the potential for enhancing digitalization project results by improving the value specification process. From the collected interview and workshop data, a list of different barrier categories was derived and further grouped into theory-driven thematic clusters.

As SMEs play an important part in the network of suppliers to larger enterprises, decreasing the gap in Industry 4.0 implementation between different enterprise categories is important (Sommer, 2015). With the emerging significance of ecosystems due to Industry 4.0 (Adner, 2017), building empirical knowledge on the SME's current practices will serve both to elucidate managerial implications and guide future research. The interviews and case studies were, thus, focused on SMEs and companies with limited digitalization experience. The subject of desired value is hard to grasp, and so, in order to identify relevant questions and get an in-depth understanding of how companies specify desired value, a data-gathering process in several steps with increasing refinements was employed. Value specification experiences from 21 companies were gathered and analyzed, so as to provide sufficient data which can then be generalized across various contexts (Leonard-Barton, 1995).

\section{Experiences from an industrial consultancy firm}

The research project was initiated by a study on the experiences of consultants from an industrial consultancy company related to 30 different industrial automation projects between 2004 and 2014. The 


\title{
Barriers to Value Specification when Carrying out Digitalization Projects
}

\author{
Sten Grahn, Anna Granlund, Erik Lindhult
}

following open-ended question, "How are your customers generally specifying desired value from digitalization projects?" was asked to three consultants within that company. Using the answers from the ensuing discussions, interview questions were generated for the systematic interviews with the companies in this study.

\section{Responses to mailed questions and subsequent} interviews with SMEs and two digital tools suppliers

A set of six questions, all centering around value specification in digitalization investments, was mailed to the engineers responsible for production development at 17 Swedish industrial SMEs. In collecting data, both responses to the questions and findings from subsequent semi-structured interviews (Walsham 1995) were used. The questions answered were:

1. How is the desired value from digitalization projects specified?

2. How is economic value ensured from digitalization projects?

3 . How is actually created value measured?

4. How is desired value over time specified?

5. What business model is used to purchase digitalization projects?

The digitalization recipient interviews above were complemented with interviews with two digital tools suppliers. The suppliers were asked to express their view on how their customers generally specify the desired value from digitalization projects, so as to provide an indication of whether recipients and suppliers are in agreement on how recipients specify the desired value.

\section{In-depth analysis of value specification practices at an international process industry company}

Finally, a series of six workshops was held with participants from one midsized international process industry company, with the purpose of identifying how outcomes of future digitalization projects could be improved, specifically, by better developing the value specification process. These workshops involved the production manager, the manager for the ITdepartment, project leaders for individual digitalization projects, and affiliated automation consultants. The following five topics were covered throughout the six workshops, namely, "why is our current project success rate limited?", "how do we specify the desired project 'success'?", "how are our organizational and project models supporting the specification of desired 'success'?", and "how could our project design be improved?". Since the digitalization project maturity of the company could not be viewed as leading-edge, their potential benefit from such discussions served as a reason for the company's interest in participating in the workshops.

\section{Data analysis}

To structure the analysis, the collected interview data was grouped into theory-driven thematic clusters.

Regarding the international midsized process industry, the more detailed information from their workshops was used to analyze potential organizational barriers as well as how actual outcomes from earlier projects had differed from specified desired outcomes. By getting an indication of how insufficient specified desired value could be, and how this attributed to unsatisfying actual outcomes, it could be assumed as part of the reason for the suboptimal results for digitalization projects within the group of SMEs. Using this information, this research was able to indicate whether any particular barrier was especially important for project outcomes.

\section{Empirical Findings}

This section summarizes answers to the aforementioned questions, interview findings, and workshop investigations, illuminating the current value specification practice in digitalization projects, as a way to identify possible barriers.

\section{Long-term experience in value specification from industrial consultants}

Responses to our open-ended questions indicated a generally limited interest in precise specification of desired value from recipients of digitalization projects. Comments from one consultant were as follows, "During all my years, I have never come across companies that really consider the questions of desired value. There generally is instead a focus on a relatively few project targets, mostly technology specifications. 'Lowered production cost' is often the desired 'value'... Limited interest in detailed value specification is also easy to understand as overhearing 'locker room talk' often reveals a wide-spread concern about outcomes from digitalization projects, regarding possible job losses and 


\section{Barriers to Value Specification when Carrying out Digitalization Projects}

\section{Sten Grahn, Anna Granlund, Erik Lindhult}

demanding new work requirements". Based on these experiences, a set of questions to the SMEs was produced leaving out the question, "How are possible disagreements avoided regarding what is 'desired value'?" as it was considered a sensitive topic.

\section{Responses to mailed questions and subsequent}

interviews with SMEs, and two suppliers of digital tools

The answers indicate that most SMEs are unaccustomed to the very concept of "specifying the desired value" from digitalization projects. Further, the responses revealed several significant categories of barriers as shown in Table 1 below. Standardized routines for equipment choice, installation, operation, and upgrading were generally followed to secure low project costs, which was assumed to also create longterm value for the company. This was not the case though, as the project routines to secure low project cost, generally generated high long-term company costs, as numerous, costly, activities were required after the projects had been 'finished', to make things function properly. Answers from suppliers supported the view that recipients generally display disinterest for specifying the desired value, or measuring the created value, as is also shown in Table 1.

\section{In-depth analysis of value specification practices at an international process industry}

The workshops identified that several project specifications were in place before digitalization projects started, such as the desired project start date, project finish date, project cost, technical specifications such as the theoretical capacity of specific machinery, ability to make measurements with a certain precision, and ability to control certain process settings. Basic specifications of what the final production machinery should do were also in place, such as "palletizing", "packaging", and "labeling". "Verified usefulness" from different stages of the project, such as explicitly useful packaging, labeling, measurements, or control, were only, however, specified to a limited extent, or not at all. This research, thus, found that the absence of specified useful communication was particularly important for the [in] ability to create increased value over time:

- Resource requirements for creating useful solutions to access process data and control signal transmissions were not specified at all. Resource requirements for these purposes, were highlighted as significant by some workshop participants who viewed these solutions as necessary for the creation of information that would be helpful for optimization. Other decisions, however, require several steps to access, such as solutions for filtering, format choice, data location solutions, and data analysis, as well as admission to data through company firewalls under IT-security policies at the company.

- Most workshop participants perceived limited problems with the above, as they had a relatively static view of digital installations, viewing them comparably to physical infrastructures such as buildings. This meant that they had a limited understanding of the benefits of being able to automatically and continuously control a system, the differences between non-optimized and optimized systems, and the improvement potential from optimization efforts. Optimization efforts were even mentioned as undesirable, as it was deemed too much of a risk that an improperly designed optimization procedure may cause costly process disturbances, or even completely stop the production process. Other workshop participants, however, highlighted that past successful optimization endeavors had generated improvements of $V / R$ beyond $30 \%$ for several processes, and that "optimizability" should be a desirable value.

The absence of useful information and communication harmed the ability for resource-effective production, as any "useful" production capacity had to be secured after the projects were finished, requiring significant resources. Possibilities to rapidly, robustly, and automatically control process settings to increase value over time - "optimizability"- were nearly non-existent, as this was dependent on things like useful information and control.

Another important factor contributing to these results was that project participants generally prioritized requirements to carry out the work and deliver the [limited] technical specifications described in the project order within time and budget constraints, instead of prioritizing non-specified production value.

Individual job descriptions, project manuals, and project instructions described what individuals should work with, how all project steps, from project idea to project handover, should be handled, and who should be 


\section{Barriers to Value Specification when Carrying out Digitalization Projects}

\section{Sten Grahn, Anna Granlund, Erik Lindhult}

responsible, Nowhere, however, did these mention the concept that desired value from work or project steps should be specified and validated.

Resources required to secure higher productivity of the installations after the automation projects had been finished, that is, the optimization efforts, were not considered project costs but rather production costs. Some workshop participants also indicated that the significant after project costs, for instance, tuning of the machinery to make it produce anything, could actually be viewed as a positive outcome for those project participants who would be beneficiaries of these resources.

Another finding showed how discussions about technology specifications, such as "power" or "speed" of machines, was generally regarded as significantly more interesting than discussions about how specifying the desired value from machine utilization could guide those choices of power and speed. The reasons for this were not clearly spelled out, but through the comments that emerged, one could gather that value was not regarded to be as "fun" a topic as power. Further, there were even concerns that thorough value specification could contribute to insights that might indicate certain "fun" and "good to have" machines as unnecessary.

The study of completed projects also showed that projects only involving limited amounts of programming (mainly physical structures) typically generated more satisfying finished products compared to installations involving significant amounts of programming. This result was indicated as being on account of the static nature of physical constructions. Here it was easy for all to see and measure if the final result created high value.

\section{Analysis}

From the empirical findings, a total of 16 categories of barriers could be identified over the five thematic clusters. For the clusters "Support" and "Other" only one category was found. The identified categories of barriers were:

- Support barrier (Su): No explicit support for value specification activity from company leadership.
- Organizational barrier (Or) categories: Limited resource allocation for value specification (Ora), Organizational structure making it too challenging to identify total company value over time, rendering value specification irrelevant (Orb), Some organizational units benefiting from low long-term resource efficiency, reducing incentives to specify a desired resource reduction (Orc), Strategic choices to not use business models where providers are remunerated for created value, reducing incentives to specify the desired value (Ord), Project models that do not require specifying desired value or evaluating created value (Ore), Project models rewarding low project cost instead of high value creation (Orf).

- Competence barrier (Co) categories: Limited competence to specify the desired value (Coa), to measure created value (Cob), to take secure advantage of information useful for optimizing operations (Coc) or, to write contracts where providers are remunerated for created value (Cod).

- Cultural barrier (Cu) categories: Habit (Cua), Belief that fulfilled technology specifications will create value (Cub), Belief that focus on one or a few values, such as "improved ergonomics" also will create other values efficiently (Cuc), Viewing value specification as an undesirable activity (Cud).

- Other barriers (Ot): Impossible to know in any detail what value an investment may create over time, making value specification irrelevant.

Representative answers for each cluster and category are found in table 1 (PA indicates a digitalization Provider Answer, WS indicates results from the workshops).

By not specifying the desired value from digitalization projects, one also erects a unfortunate barrier from other vital specifications that are important for optimizing systems and resources effectively, so as to create an increase in value over time:

- Without a clearly defined desired value, specifying how to measure created value becomes less relevant. "Useful" measurements and information (such as that for effective system control) were never mentioned as desired value. 


\section{Barriers to Value Specification when Carrying out Digitalization Projects} Sten Grahn, Anna Granlund, Erik Lindhult

Table 1. Cluster, category, and representative answer or result from the workshops

\begin{tabular}{|c|c|c|}
\hline Cluster & Category & Representative answer, or result from the workshops (WS) \\
\hline Su & & $\begin{array}{l}\text { No indication that leadership requires the desired project value to be } \\
\text { specified }\end{array}$ \\
\hline \multirow[t]{8}{*}{ Or } & Ora & $\begin{array}{l}\text { "We have very limited resources to specify...how created value should be } \\
\text { measured or to what degree the IT-department's technology specifications will } \\
\text { actually generate value for the Production department." }\end{array}$ \\
\hline & Orb & $\begin{array}{l}\text { (PA) "Desired values are 'faster processes', 'fewer errors', that could be relatively } \\
\text { easy to specify and measure if customers were more interested in doing that." }\end{array}$ \\
\hline & Orc & $\begin{array}{l}\text { (WS) The organizational structure makes it too challenging to identify total } \\
\text { company value over time, making value specification irrelevant. }\end{array}$ \\
\hline & $\begin{array}{l}\text { Orc } \\
\text { Ord }\end{array}$ & $\begin{array}{l}\text { "We are [also] aware that these 'savings' in specification resources generate } \\
\text { substantial resource consumption later on, to fix everything that does not work } \\
\text { after a digitalization project has been 'finished."' }\end{array}$ \\
\hline & & $\begin{array}{l}\text { (WS) Limited incentives for organizational units to maximize total company } \\
\text { value over time }\end{array}$ \\
\hline & Orf & $\begin{array}{l}\text { "Payments to digital tool providers are not connected to created value in our } \\
\text { company... Value focused contracts doesn't suit our current business model..." }\end{array}$ \\
\hline & & $\begin{array}{l}\text { (WS) Project models only focused on securing technology specifications, not } \\
\text { on creating value }\end{array}$ \\
\hline & & (WS) Strong incentives to minimize short term project/technology costs \\
\hline \multirow[t]{4}{*}{ Co } & $\operatorname{Co}(a-d)$ & (WS) Limited knowledge of how to specify, to measure, evaluate and pay for \\
\hline & Cob & created value \\
\hline & Coc & $\begin{array}{l}\text { We have no method to further measure the value of IT projects except assuming } \\
\text { that automating the CAD process will lead to value." }\end{array}$ \\
\hline & & $\begin{array}{l}\text { (WS) Percieved IT-security and Production risk: Optimization too challenging: } \\
\text { 'Optimizability' irrelevant value }\end{array}$ \\
\hline \multirow[t]{5}{*}{$\mathrm{Cu}$} & Cua & $\begin{array}{l}\text { "We do not have any method for evaluating the value of our projects. Instead, we } \\
\text { look at the overall figures we have in the business. For example, delivery security, } \\
\text { number of completed orders or 'the last line in the annual accounts."” }\end{array}$ \\
\hline & Cub & "We evaluate technical specifications...rather than the value of the functions." \\
\hline & Cuc & $\begin{array}{l}\text { "The IT projects we have, have currently focused on reducing lead-time by } \\
\text { reducing the need for manual working hours. The value for the company has } \\
\text { been implicitly assumed concerning the nature of the project."If there are } \\
\text { ergonomic improvements, it is always worth it." }\end{array}$ \\
\hline & Cud & $\begin{array}{l}\text { (PA)"I wish they [customers] focused more on value, but the focus is almost only } \\
\text { on estimated cost reduction." }\end{array}$ \\
\hline & & (WS) Value specification is viewed as an undesirable/boring activity \\
\hline \multirow[t]{2}{*}{$O t$} & & $\begin{array}{l}\text { "The total impact of investments over time is difficult or impossible to predict in } \\
\text { any detail" }\end{array}$ \\
\hline & & $\begin{array}{l}\text { (WS) "Impossible" to know the future value from digitalization in detail, why } \\
\text { specify? }\end{array}$ \\
\hline
\end{tabular}




\section{Barriers to Value Specification when Carrying out Digitalization Projects}

\section{Sten Grahn, Anna Granlund, Erik Lindhult}

- Without useful information, specifying the value "optimizability", that is, the possibilities for effective, continuous system optimization (system control to increase $\mathrm{V} / \mathrm{R}$ over time) is not relevant, as this is dependent on useful measurements of $V, R$, and process settings.

Competence and organization are also important barriers to specifying "optimizability" as this requires an understanding of the concept, as well as continuous access to useful information and control signals. Securing this may prove a challenge for company ITsecurity and organizational policies in order to determine who can do it, when, and how. By some people's indications, this would present many hard challenges (Coc) to overcome and would present a path not worth pursuing.

In addition to IT-security risks, production risks were also indicated as a competence barrier to "optimizability" specification. Concerns that safe constraints for process settings would be challenging to establish indicated that identification and fixing of process settings that "work" is more interesting than optimization (Coc).

We, thus, interpret our findings as demonstrating how the lack of leadership and organizational support is a crucial barrier to value specification. Within the thematic clusters identified from the literature, we identified several different types of barriers, such as various organizational barriers that may work in concert to bar value specification efforts. Our findings also indicate that this may have a significant impact on specification competence barriers, as well as on cultural barriers. The lack of precisely specified desired value makes the specification of value measurements, value control, and optimizability irrelevant objectives, while perceived risks and challenges connected to optimization efforts further strengthen the "irrelevance" barrier.

The findings from the workshops showed that imprecise value specification led to various unsatisfying project outcomes. For each of the projects studied in the workshops, the consequences implied that significant resources were required to facilitate effective utilization of the digital installations. To adjust production when, for example, products changed, and to effectively optimize the production was inconvenient at best, if optimization was even possible after the digitalization projects had been "finished". "Inflexible solutions" also served as a reason for many SMEs participating in the interview study. As the SMEs and the process industry responded similarly to our questions, we found it reasonable to assume that the SMEs imprecise or absent value specifications contributed to their "inflexible solutions" outcomes, as it did for the process industry.

Despite the identified or assumed (as in the case for the interviewed SMEs) unsatisfactory project outcomes which resulted from unprecise value specifications, this practice was generally uncontroversial, and actually seen as beneficial for several reasons. For example, it avoids a potentially resource-demanding, "wasteful" challenging, or boring activity. It also makes it easier to keep precise information of how equipment and projects will increase value classified for digital tool providers.

In summary, we discovered several multi-faceted barriers companies face when looking at increasing resources for specifying desired value from digitalization projects. The findings also indicate that challenges for digital providers may be rooted in the difficulty customers face in trying to identity a specific value for which to pay; attempting to servitize their offers and find customers willing to shift the business model from paying for advanced digital technology to paying for created customer value often proves quite difficult.

\section{Conclusions and Suggestions for Future Research}

Our findings indicate that improving value specification could be a significant challenge. The managerial implications for SMEs propose that methods to reduce the "alarming" failure rate of digitalization projects must address and overcome several different barriers, including the identification of what "failure" and "success" mean for whom in the organization, and a reflection on the difference between the short-term resource-efficient following of organizational and project models and efficient securing of technical specifications, and the long-term resource-effective ability to create company value (Sink \& Tuttle, 1989).

Another implication of our research findings is that digitalization providers that attempt to "servitize" their offers and focus on creating customer value, rather than sell advanced technology, may benefit from attempting to identify the fairly limited number of customers who have a clear picture of what value they want to create 


\section{Barriers to Value Specification when Carrying out Digitalization Projects}

\section{Sten Grahn, Anna Granlund, Erik Lindhult}

with their digitalization efforts.

Since the front-end project stage is currently not clearly understood within academia (Williams et al., 2019), this study contributes to increased understanding and insight on the topic. It also advances servitization and value research by taking the digitalization value recipient perspective, which few servitization studies cover at present. Further, it suggests an indicative structure of different barriers to value specification, and, thus, barriers to servitization efforts, and proposing that methods to overcome those barriers should be developed. It also recommends that the development of such methods must consider several questions which ought to be investigated in future studies, for example, what efforts may be most effective when attempting to dismantle existing value specification barriers.

\section{Acknowledgment}

This study was part of the research projects: Lean Automation Development (LEAD), "Automated design of production tools" (ADaPT), "Efficient automation for adapted products in Swedish factories" (e-Factory) financed by the Swedish Agency for Innovation Systems (Vinnova), and "Sustainable Textile Barriers" (Texbar) financed by Mistra Innovation. The research was performed in the context of the XPRES environment at RISE IVF $\mathrm{AB}$ and $\mathrm{MDH}$.

\section{References}

Adner, R. 2017. Ecosystem as Structure: an actionable construct for strategy. Journal of Management, 43(1): 39-58.

DOI: https://doi.org/10.1177/0149206316678451

Badewi, A. 2016. The Impact of Project Management (PM) and Benefits Management (BM) Practices on Project Success: Towards Developing a Project Benefits Governance Framework. International Journal of Project Management 34 (4): 761-778. DOI:10.1016/j.ijproman.2015.05.005.

Baines, T. Lightfoot, H.W. Evans, S. Neely, A. Greenough, R. Peppard, J., Wilson H. 2007. State-ofthe-art in product-service systems. Proceedings of the Institution of Mechanical Engineers, Part B: Journal of Engineering Manufacture, 221 (10): 15431552.

DOI: 10.1243/09544054JEM858

Breese, R., Jenner, Serra, S.C.E.M. \& Thorp, J. 2015. Benefits Management: Lost or Found in Translation. International Journal of Project Management 33 (7): 1438-1451.

DOI:10.1016/j.ijproman.2015.06.004.

Brynjolfsson, E. \& McAfee, A. 2014. The Second Machine Age: Work, Progress, and Prosperity in a Time of Brilliant Technologies, W. W. Norton \& Company, New York, USA.

Carlborg, P., Kindström, D. \& Kowalkowski, C. 2014. The Evolution of Service Innovation Research: a critical review and synthesis, The Service Industries Journal, $\quad 34(5)$ : 373-398. DOI: https://doi.org/10.1080/02642069.2013.780044

Dass, K. 2014. Leading Enterprise Wide Projects. Paper presented at PMI ${ }^{\circledR}$ Global Congress 2014- North America, Phoenix, AZ. Newtown Square, PA: Project Management Institute.

de Geus, A. 1988. Planning as Learning. March Issue NBR

Edkins, A., \& Smith, A. 2012. Designing the Project. In Project Governance: Getting Investments Right, edited by Terry Williams and Knut Samset, 135-174. London, England: Palgrave Macmillan.

Gottlieb, J., \& Willmott, P. 2014. The Digital Tipping Point.

http://www.mckinsey.com/insights/business_techn ology/ the_digital_tipping_point mckinsey_global_survey_results. Accessed 3 August 2016 McKinsey Global Survey Results

Grahn, S., Granlund. A., \& Lindhult. E. 2020. How to Deal with Differing Views of Resource Efficiency when Carrying Out Digitalization Projects, SPS2020 Conference. 


\title{
Barriers to Value Specification when Carrying out Digitalization Projects
}

\author{
Sten Grahn, Anna Granlund, Erik Lindhult
}

DOI: https://doi.org/10.3233/atde200144

Gutsche, R. 2014a. Survival of the Smartest - Which Companies Will Survive the Digital Revolution? https://www.kpmg.com/DE/de/Documents/surviva l-of-the-smartest-2014- kpmg-en.pdf. Accessed 1 August 2016

Ismail, N. 2018. Why IT Projects Continue to Fail at an Alarming Rate, Information Age. https://www.information-age.com/projectscontinue-fail-alarming-rate-123470803\% Accessed 26 April 2021

Leonard-Barton, D. 1995. Wellsprings of Knowledge. Boston: Harvard Business School Press. DOI:

https://www.hbs.edu/faculty/Pages/item.aspx?num $=72$

Lerch, C. \& Gotsch, M. 2015. Digitalized ProductService Systems in Manufacturing Firms: A Case Study Analysis. Research-Technology Management, 58(5): $\quad 45 \quad 52$. DOI: https://doi.org/10.5437/08956308x5805357

Matthyssens, P. \& Vandenbempt, K. 2010. Service Addition as Business Market Strategy: Identification of transition trajectories. Journal of Service

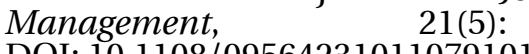

DOI: $10.1108 / 09564231011079101$

Morris, P. 2009. Implementing Strategy through Project Management: The Importance of Managing the Project Front-End. In Making Essential Choices with Scant Information: Front-End Decision Making in Major Projects, edited by Terry Williams, Knut Samset, and Kjell Sunnevåg. London, England: Palgrave Macmillan: 39-67.

Müller, J.M., Kiel D. \& Voigt, K.I. 2018. What Drives the Implementation of Industry 4.0? The Role of Opportunities and Challenges in the Context of Sustainability. Sustainability, 10(1): 247-271. DOI: https://doi.org/10.3390/su10010247

Ormazabal, M., Prieto-Sandoval, V., Jaca, C., Santos, J., 2016. An Overview of the Circular Economy Among SMEs in the Basque Country: a multiple case study. $J$. Ind. Eng. Manag. 9, $1047 \mathrm{e} 1058$. DOI: https://doi.org/10.3926/jiem.2065.

Project Management Institute. 2016. The Strategic Impact of Projects: Identify benefits to drive business results. PMI Pulse of the Profession ${ }^{\circledR}$. Newtown Square, PA: Project Management Institute.

Raddats, C. Kowalkowski, C. Benedettini, O. Burtond, J. \& Gebauere, H. 2019. Servitization: A contemporary thematic review of four major research Streams, Industrial Marketing Management, Article in press. DOI:

https://doi.org/10.1016/j.indmarman.2019.03.015

Rexfelt, O. \& Ornäs, V. H., 2009 Consumer Acceptance of Product-Service Systems: Designing for relative advantages and uncertainty reductions. Journal of
Manufacturing Technology Management, 20(5): 674699.

DOI: 10.1108/17410380910961055

Rifkin, J. 1995. The End of Work. Penguin, New York, USA.

Rifkin, J. 2014. The Zero Marginal Cost Society: The Internet of Things, the Collaborative Commons, and the Eclipse of Capitalism. Palgrave Macmillan, New York,

DOI: https://doi.org/10.5860/choice.186403

Sink, D.S. \& Tuttle, T.C. 1989. Planning and Measurement in Your Organization of the Future. $I E$ Press, Norcross, GA.

Sommer, L. 2015. Industrial Revolution-Industry 4.0: Are German Manufacturing SMEs the First Victims of this Revolution? Journal of Industrial Engineering and Management, 8(5): 1512-1532. DOI: https://doi.org/10.3926/jiem.1470

Stahel, W.R. 2010. The Performance Economy. Palgrave Macmillan, Basingstoke, England

Terlizzi, M.A., Albertin, A.L., \& de Moraes, H.R.D.O.C. 2017. IT Benefits Management in Financial Institutions: Practices and Barriers. International Journal of Project Management, 35(5): 763-782. DOI: 10.1016/j.ijproman.2017.03.006.

Walsham, G. 1995. Interpretive Case Studies in IS Research: Nature and Method. European Journal of Information Systems, 4(2): 74-81. DOI: https://doi.org/10.1057/ejis.1995.9

Williams, T., Vo, H., Samset, H. \& Edkins, A. 2019. The front-end of projects: a systematic literature review and structuring. Production Planning \& Control, 30(14):

1137-1169.

DOI: 10.1080/09537287.2019.1594429

World Economic Forum. Introducing the Digital Transformation Initiative. Accessed 26 April 2021: https://reports.weforum.org/digitaltransformation/introducing-the-digitaltransformation-initiative/ 


\title{
Barriers to Value Specification when Carrying out Digitalization Projects
} Sten Grahn, Anna Granlund, Erik Lindhult

\begin{abstract}
About the Authors
Sten Grahn has several years of experience in the manufacturing and energy industries, including several leading industrial roles and responsibilities. He currently holds a position as senior lecturer at the Division of Product Realization, Mälardalen University. He also holds a position as a researcher for RISE IVF AB. His main research interests concern system optimization and automation, especially identifying how resource efficiency efforts should be balanced to generate environmentally sustainable business, as well as long-term profits.

Anna Granlund holds a position as senior lecturer at the Division of Product Realization, Mälardalen University. Her research interests are in the area of production development, specifically technology development in the manufacturing industry. Her research mainly addresses strategy and organizational aspects of technology development, as well as coordinating production and technology development in IMNs. She has thirteen years of experience coproducing research projects in the areas of automation development and managing production development in IMNs.

Erik Lindhult holds a position as senior lecturer at the Division of Innovation Management, Mälardalen University, Sweden. His main area of research is service innovation, systemic innovation, and valuedriven innovation. He has been engaged in research, education, and with the international research community for several decades on participatory, collaborative, and democratic approaches to action research and innovation, as well as entrepreneurship for sustainable social development.
\end{abstract}

Citation: Grahn, S., Granlund, A., Lindhult, E. 2021. Barriers to Value Specification when Carrying out Digitalization Projects. Technology Innovation Management Review, 11(5): 54-64.

http://doi.org/10.22215/timreview/1442

Keywords: Value specification, resource-efficiency, effectiveness, automation, digitalization 